\title{
Detection of single tumor cell resistance with aptamer biochip
}

\author{
LIXUE WANG $^{1}$, QIN ZHENG $^{1}$, QUAN'AN ZHANG $^{1}$, HANFENG XU $^{1}$, \\ JINLONG TONG ${ }^{1}$, CHUANDONG ZHU $^{1}$ and YUAN WAN ${ }^{2}$ \\ ${ }^{1}$ Department of Oncology, The Second Affiliated Hospital of Nanjing, Southeast University, Nanjing, Jiangsu 210003, \\ P.R. China; ${ }^{2}$ University of South Australia, Mawson Lakes Campus, Mawson Lake, Adelaide, SA 5095, Australia
}

Received May 10, 2012; Accepted August 9, 2012

DOI: $10.3892 / \mathrm{ol} .2012 .890$

\begin{abstract}
In this study, a novel RNA aptamer biochip was developed for tumor cell capture and detection of single cell resistance. This biochip consists of a polydimethylsiloxane (PDMS) cover containing a channel for introducing cells and sustaining their activity and microelectrode matrix on a silicon dioxide layer. Epidermal growth factor receptor (EGFR) aptamers which specifically identify and isolate tumor cells were attached in the gap between two electrodes. After cell biochip incubation, surplus tumor cells were removed, and those dwelling on the intervals were further analyzed. When resistance measurement was completed, these cells were flushed away via controlled flow acceleration, and were collected for further analysis. The results demonstrate the convenience and efficiency of using anti-EGFR aptamer biochips for the detection of single cell resistance. This novel aptamer biochip may be used for the isolation of circulating tumor cells from peripheral blood and cell counting, or be assembled with other lab-on-a-chip components for follow-up gene and protein analysis.
\end{abstract}

\section{Introduction}

The biological research on single cell isolation and analysis has grown rapidly over the past three decades $(1,2)$. As technology evolves, processes such as protein analysis, gene amplification, single nucleotide polymorphism (SNP) detection and RNA quantification have further stimulated its development. Enzyme-linked immunosorbent assay (3), flow cytometry (4), optical tweezers (5), capillary electrophoresis (6) and dielectrophoresis (DEP) (7) have proven to be the methods of choice for the quantitative analysis of cell populations. Moreover,

Correspondence to: Dr Qin Zheng, Department of Oncology, The Second Hospital of Nanjing, Southeast University, 1-1 Zhongfu Street, Nanjing, Jiangsu 210003, P.R. China

E-mail: txzzzq@sina.com

Dr Yuan Wan, University of South Australia, Mawson Institute, Adelaide, SA 5095, Australia

E-mail: yuan.wan@unisa.edu.au

Key words: circulating tumor cell, aptamer biochip, cell isolation electrical impedance spectroscopy is also a common tool for cell counting and analysis (8-13) due to its rapid speed, low cost and high sensitivity. However, most of these approaches are used for a rough estimate of cell numbers since the changes in cell suspension concentration and impedance measurements are proportional. In practical application, the detection of small numbers of cells and counting their exact amount is a very challenging problem, particularly in the detection of circulating tumor cells (CTCs), which may be as low as one CTC among one million normal hematopoietic cells. Since the specific recognition between cells expressing antigens and complementary antibodies could cause cells to adhere on the surface, researchers immobilized the antibodies (14-17) in the gap between two electrodes to facilitate impedance detection. However, the specificity of antigen-antibody is an issue (18). When target molecules have competing molecules with similar structures or similar interactions with epitopes of probe antibodies, it may produce false results. Aptamers, nucleic acids or peptide sequences, found by in vitro selection based on their binding ability to specific molecular targets, have recently emerged as alternative probe molecules (19). In addition to their natural exclusion against biofouling, aptamers may be chemically synthesized, and labeled/loaded with various reporters/payload. Aptamers have been shown to have many more advantages, including higher specificity and affinity, stability at various salt and ionic conditions, and reversible denaturation (20). In previous research, an anti-epidermal growth factor receptor (EGFR) aptamer biochip was shown to specifically identify and isolate mouse-derived tumor cells $(21,22)$. In this study, we attached the aptamer in the gap between the two electrodes and detected the cell resistance following cell capture. Following this, the captured cells could be flushed via controlled flow acceleration (23) that would not harm the cell itself, and these cells could be collected for further analysis, including protein detection and quantification, SNP detection and RNA extraction. The solid results indicate that this aptamer biochip could be used in single cell resistance measurement and cell number counting.

\section{Materials and methods}

All chemicals were obtained from Sigma-Aldrich (St. Louis, MO, USA) unless otherwise noted. The study was approved by the Ethics Comittee of The Second Affiliated Hospital of Nanjing, Southeast University, Nanjing, Jiangsu, P.R. China. 
Aptamer biochip preparation. The 4-inch wafer was cleaned in piranha solution $\left(\mathrm{H}_{2} \mathrm{O}_{2}: \mathrm{H}_{2} \mathrm{SO}_{4}\right.$ at a $1: 3$ ratio) for $10 \mathrm{~min}$ at $90^{\circ} \mathrm{C}$. After rinsing with deionized (DI) water and drying under nitrogen, the wafer was coated with positive photoresist PR1-500A (Futurrex Inc., Franklin, NJ, USA), spun at 3,000 rpm for $40 \mathrm{sec}$ and baked at $115^{\circ} \mathrm{C}$ for $2 \mathrm{~min}$. The exposure energy was approximately $240 \mathrm{~mJ} / \mathrm{cm}^{2}$. The exposed area was then removed with relevant developer. Chromium and aurum were orderly deposited with AJA E-beam at thicknesses of 20 and $100 \mathrm{~nm}$, respectively. Finally, acetone was used for lift-off. The width of each electrode was $5 \mu \mathrm{m}$. Since the diameter of tumor cell was approximately $18-30 \mu \mathrm{m}$, the measurements of the gap between the two electrodes were set at $2.5,7.5,13,18,23$ and $28 \mu \mathrm{m}$ to investigate the optimal distance.

Polydimethylsiloxane (PDMS) cap preparation. The method used to form channels on PDMS is based on previously published procedures (24). The wafer cleaning was performed as mentioned above. The wafer was coated with negative photoresist SU 8-50 (MicroChem Corp., Newton, MA, USA) and spun at 1,000 rpm for $30 \mathrm{sec}$. It was soft-baked at 65 and $95^{\circ} \mathrm{C}$ for 10 and $30 \mathrm{~min}$, respectively. The exposure energy was approximately $560 \mathrm{~mJ} / \mathrm{cm}^{2}$. The wafer was then post-baked at 65 and $95^{\circ} \mathrm{C}$ for 1 and $10 \mathrm{~min}$, respectively. The unexposed SU 8-50 was removed by developer. A 10:1 (w/w) mixture of PDMS oligomer and cross-linking agent, which had been degassed under a vacuum, was poured onto the SU 8 master. The PDMS was removed from the mold to form a channel pattern on the PDMS after $30 \mathrm{~min}$ of curing at $80^{\circ} \mathrm{C}$. The channel on the PDMS was $15 \mathrm{~mm}$ in length, $1 \mathrm{~mm}$ in width and $100 \mu \mathrm{m}$ in height. Two holes with a diameter of $2 \mathrm{~mm}$ were cut out of the PDMS with a punch.

Aptamer attachment. The attachment method was adapted from previous studies $(25,26)$. The biochip surface was cleaned by ultraviolet ozone for $10 \mathrm{~min}$ at room temperature. After rinsing with DI water and drying under nitrogen, the biochips were immersed in a 19:1 (v/v) methanol:DI water solution containing 3\% (3-Aminopropyl)trimethoxylilane (APTMS) for $30 \mathrm{~min}$ at room temperature. Devices were sequentially rinsed with methanol and DI water. Silanized devices were then immersed in a dimethylformamide (DMF) solution containing $10 \%$ pyridine and $1 \mathrm{mM}$ phenyldiisothiocyanate (PDITC) for $2 \mathrm{~h}$. Each device was then washed sequentially with DMF and 1,2-dichloroethane and dried under a stream of nitrogen. A volume of $10 \mu \mathrm{M}$ DNA capture probe (5'-amino-CTG GTC ATG GCG GGC ATT TAA TTC-3') was prepared in DI water with $1 \%(\mathrm{v} / \mathrm{v})$ $\mathrm{N}, \mathrm{N}$-diisopropylethylamine (DIPEA). A volume of $5 \mu \mathrm{l}$ solution was placed onto each device and allowed to incubate in a humidity chamber at $37^{\circ} \mathrm{C}$ overnight. Each device was sequentially washed with methanol and diethylpyrocarbonate (DEPC)-treated DI water $(0.02 \% \mathrm{v} / \mathrm{v})$. Unreacted PDITC moieties on the surface were deactivated by immersion in $50 \mathrm{mM}$ 6-amino-1-hexanol and $150 \mathrm{mM}$ DIPEA in DMF for $5 \mathrm{~h}$. Each device was then sequentially rinsed with DMF, methanol and DEPC-treated DI water. The incubator was cleaned with ribonuclease (RNase)-free spray (Argos Technologies, Inc., Elgin, IL, USA) and DEPC-treated DI water three times. A volume of $5 \mu \mathrm{l} 1 \mu \mathrm{M}$ anti-EGFR RNA aptamers (5'-GGC GCU CCG ACC UUA GUC UCU GUG CCG CUA UAA UGC ACG GAU UUA AUC GCC GUA GAA AAG CAU GUC AAA GCC GGA ACC GUG UAG CAC AGC AGA GAA UUA AAU GCC CGC CAU GAC CAG-3') in $1 \mathrm{x}$ annealing buffer $[10 \mathrm{mM}$ (pH 8.0) Tris, $1 \mathrm{mM}$ (pH 8.0) EDTA and $100 \mathrm{mM} \mathrm{NaCl}$ ] were placed onto each device. After $1 \mathrm{~h}$ hybridization at $37^{\circ} \mathrm{C}$, devices were washed with $1 \mathrm{x}$ annealing buffer and DEPC-treated DI water, respectively, for $5 \mathrm{~min}$.

Mouse-derived tumor cell culture. Neural stem cells (NSC) harvested from Ink4a/Arf-/- mice were infected with a retrovirus encoding activated mutant EGFR (EGFRvIII). To assess tumorigenicity, $2 \times 10^{4}$ cells from early passage EGFR-transduced NSCs from Ink4a/Arf-/- mice were transplanted orthotopically into the brains of adult SCID mice. The Ink4a/Arf-/- EGFRvIII NSC cultures rapidly developed tumors in the brains of the mice. The histology of Ink4a/Arf-/- EGFRvIII NSCs tumors were noted to exhibit cellular pleomorphism with high mitotic activity, invasion into normal parenchyma, migration along blood vessels and white matter tracts (data not shown). Cells were suspended in a chemically defined serum-free Dulbecco's modified Eagle's medium (DMEM)/F-12 medium, consisting of mouse EGF (20 ng/ml; Peprotech, Rocky Hill, NJ, USA), bFGF (20 ng/ml; Peprotech), B27 supplement (1x; Invitrogen Life Technologies), insulin-transferrin-selenium-X (1x; Invitrogen Life Technologies), penicillin-streptomycin (100 units/ml, $100 \mu \mathrm{g} / \mathrm{ml}$; Hyclone UK Ltd., Cramlington, UK) and plated at a density of $3 \times 10^{6}$ live cells $/ 60 \mathrm{~mm}$ plate. Cells were able to undergo clonal expansion and form orthotopic tumors (data not shown).

Meninge-derived primary fibroblast culture. Rat-derived primary meningeal fibroblasts were obtained from three-day-old rat pups. Briefly, meninges were peeled from the cerebral cortices then processed by incubation for $30 \mathrm{~min}$ in collagenase $(0.5 \%), 20 \mathrm{~min}$ in trypsin/EDTA $(0.06 \%)$ and then triturated. Following trituration, the cells were plated in T-75 tissue culture flasks in DMEM/F-12 medium containing $10 \%$ fetal bovine serum and allowed to grow for one week to confluence.

Cell elution. For better observation, we used glass in place of silicon wafer. PDMS covers were immersed into $70 \%$ ethanol for 30 min for sterilization, then DEPC-treated DI water was used to clean the ethanol remains and the covers were dried by nitrogen. The PDMS surface was treated by UV-ozone for 5 min to make it more hydrophilic, and then attached to the biochip surface. Approximately $6 \mu \mathrm{l} 1 \mathrm{x}$ phosphate-buffered saline (PBS) with $5 \mathrm{mM} \mathrm{Mg}^{2+}$ was first injected into the channel to assist the formation of the hairpin structure, and removed before cell seeding. Cell suspension ( $6 \mu 1$; 1x PBS; pH 7.3) was injected into the channel via the inlet on the PDMS cover. After that the devices were incubated for $30 \mathrm{~min}$ at $37^{\circ} \mathrm{C}$ (27). One end of the two tubes (diameter, $2 \mathrm{~mm}$ ) was connected to the PDMS cover inlet and outlet holes; the other end of two tubes was connected to the syringe pump (Harvard Bioscience, MA, USA). The flow velocity was digitally controlled. The glass was 

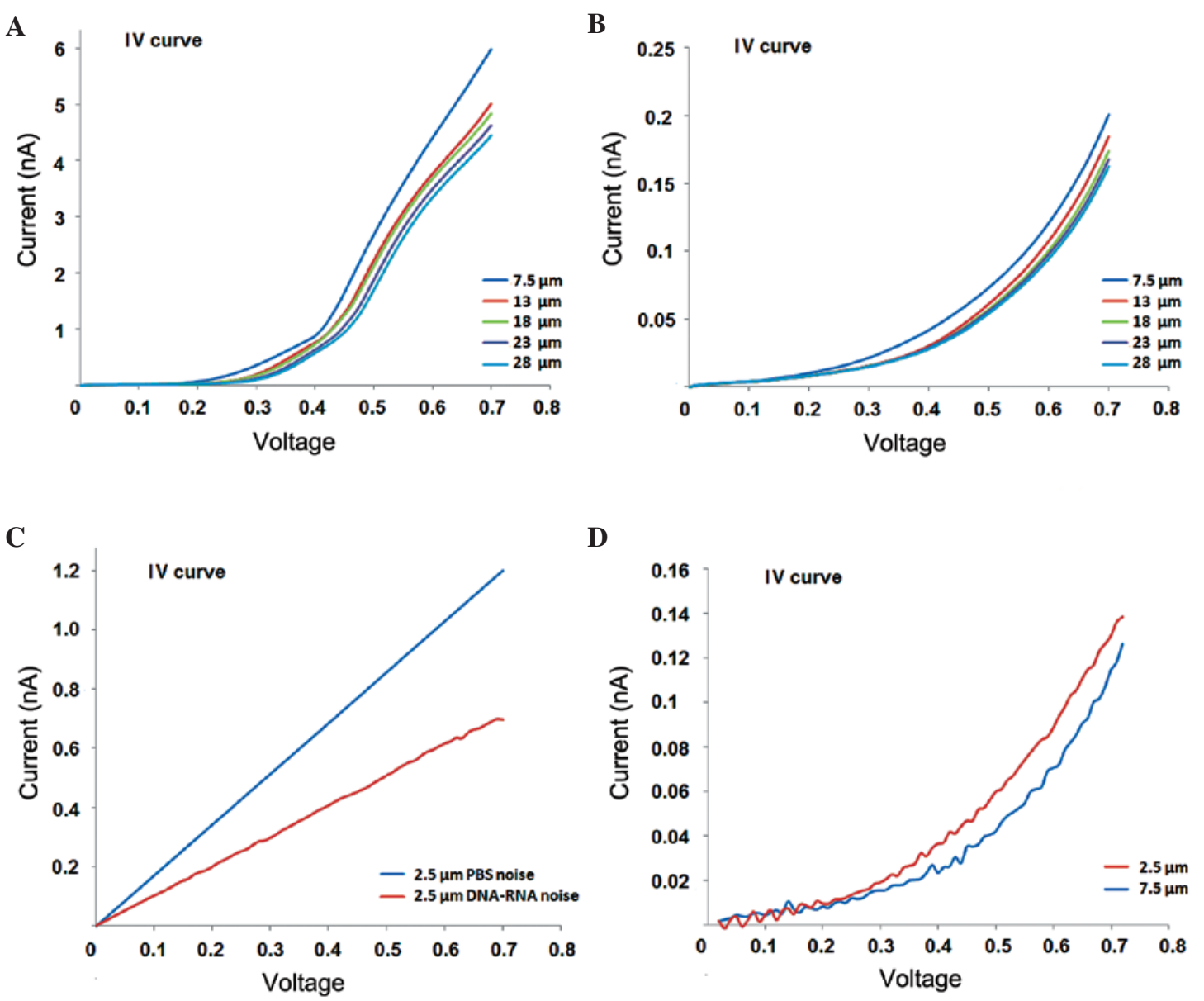

Figure 1. Current to voltage (IV) curves of 1x PBS background, DNA-RNA background and cell resistance. The voltage range is from 0-0.7 V. (A) Currents observed with 7.5, 13, 18, 23 and $28 \mu \mathrm{m}$ gaps between electrodes in PBS. (B) Currents observed with 7.5, 13, 18, 23, and $28 \mu \mathrm{m}$ gaps in PBS solution after DNA-RNA complex was available on the biochip surface. (C) Current with $2.5 \mu \mathrm{m}$ gap before and after DNA-RNA complex was introduced. (D) Currents after tumor cells were placed between electrodes. PBS, phosphate-buffered saline.

placed under an optical microscope to observe the cell eluting process.

Tumor cell capturing and resistance detection. The substrate treatment, DNA attachment, RNA hybridization, cell seeding and incubation were performed as mentioned above. The devices were then washed with sterilized 1x PBS solution under controlled flow to ensure that the unattached cells were removed. The resistance was detected by Electrical Test 4155C (Agilent Technologies, Inc., Santa Clara, CA, USA) at room temperature.

\section{Results}

PBS background detection. Sterilized PBS ( $\mathrm{pH} 7.3$ ) is a buffer commonly used in cell experiments, containing potassium phosphate monobasic $\left(\mathrm{KH}_{2} \mathrm{PO}_{4}\right)$, sodium phosphate dibasic $\left(\mathrm{Na}_{2} \mathrm{HPO}_{4}\right)$, sodium chloride $(\mathrm{NaCl})$ and potassium chloride $(\mathrm{KCl})$. These ions give the solution a certain electrical conductivity. After injecting approximately $3 \mu \mathrm{l} 1 \mathrm{x}$ PBS into the chamber, a voltage of $0-0.7 \mathrm{~V}$ was exerted at 71 intervals. We took 24 results for each distance between electrodes and calculated the mean value. As shown in Fig. 1A, the current in the 7.5, 13, 18, 23 and $28 \mu \mathrm{m}$ gap increased with the increase of voltage, but it decreased with the increase of distance. From $0-0.2 \mathrm{~V}$, the current was approximately $10^{-12}-10^{-11} \mathrm{~A}$; from $0.2-0.7 \mathrm{~V}$, it was approximately $10^{-10}-10^{-9} \mathrm{~A}$. If we do not consider the current caused by ion diffusion, or the slight change in PBS concentration caused by the limited hydrolysis, we are able explain the curve from two major aspects. (i) If we consider PBS to be a resistance device between the two electrodes, an approximation can be obtained from the following equations:

i) $\frac{1}{\rho}=\sigma=\left(\sum_{i} n_{i} \mu_{i}\right) e$

From i) and ii) $R=\rho \frac{l}{S}=\frac{l}{\sigma S}$ above, we can deduce equation iii):

$$
\text { iii) } I=\frac{U}{R}=U \frac{\sigma S}{l}=\frac{U S\left(\sum_{i} n_{i} \mu_{i}\right) e}{l}
$$

where $p$ is resistivity conductivity; $n$ is ion quantity; $\mu$ is mobility of relevant ion; $e$ is elementary charge; $l$ is the distance between the two electrodes; $S$ is the overlap area of the two electrodes; and $U$ is the voltage between the two electrodes. 
In PBS, the mobility of $\mathrm{H}^{+}$is far greater than that of other ions such as $\mathrm{Na}^{+}, \mathrm{K}^{+}, \mathrm{Cl}^{-}$and $\mathrm{PO}_{4}{ }^{3-}$. The $\mathrm{H}^{+}$comes from the ionizing of $\mathrm{H}_{2} \mathrm{PO}^{4-}, \mathrm{HPO}_{4}{ }^{2-}$ and $\mathrm{H}_{2} \mathrm{O}$. The increasing voltage could facilitate the ionization process, so $R$ will correspondingly decrease. As a result, the current increases with the increase of voltage. However, with constant voltage, $R$ would be a constant, and the current would depend on the distance between the two electrodes. Therefore, with an increase in the distance, the current decreases slightly. (ii) However, from $0-0.2 \mathrm{~V}$, the increase in current was extremely slow. The curves in this section show the polarization behavior of PBS. Potential varies in paraelectric materials depending on the working temperature; at a higher temperature the motion of electrons become more intense, this directly affects potential changes. On the contrary, in this study voltage influenced the polarization process of PBS by directly affecting material ionization. At the anode and cathode, relevant anions and cations formed sheaths around the electrodes. With the increase of voltage, ions were able to break through these sheaths and form a circuit. The results with a $2.5-\mu \mathrm{m}$ gap between electrodes are shown in Fig. 1C. The current displayed a linear increase from $-3.81 \times 10^{-8} \mathrm{~A}$ at $0 \mathrm{~V}\left(\mathrm{SD}, 9.69 \times 10^{-9}\right)$ to $9.89 \times 10^{-4} \mathrm{~A}$ at $0.7 \mathrm{~V}$ $\left(\mathrm{SD}, 3.46 \times 10^{-5}\right)$. This linear curve may have been caused by the contact of two sheaths. Therefore, we surmise that the range of the sheath is $1.25-3.75 \mu \mathrm{m}$. We also noted that the standard deviation of current with the $2.5-\mu \mathrm{m}$ gap gradually increased with the increase of voltage. Conversely, the standard deviations with the other distances varied from $10^{-12}-10^{-10}$. This difference may have been caused by the equipment itself. Since the current intensity using a $2.5-\mu \mathrm{m}$ gap was almost $10^{5}$ times larger than that observed with other distances, the detection error would correspondingly increase. Additionally, the detection time on each point of 71 intervals is not uniform, which might also cause additional errors. However, the differences were still kept to approximately $1 \%$. The measurements were subject to the limited experimental conditions since we were unable to detect the ion quantity and mobility or improve the measurement accuracy; however, these results are sufficient for explaining the phenomena.

DNA and aptamer background detection. In this step, we attached a DNA probe and aptamer on the biochip surface, and then detected the current to voltage (IV) curve variance. The whole process was similar to the previous step. In previous studies $(28,29)$, electrophoresis was used to detect SNP and DNA methylation. Single-base mismatches could be distinguished from complete matches. Although electrophoresis can dismiss the complete matching bases, the denature speed is extremely low. In these studies, even after $1 \mathrm{~h}$ of electrophoresis, strong fluorescence signals were still detected. In our experiment, we exerted $0-0.7 \mathrm{~V}$ voltages on the two electrodes, and the detection time was approximately $10 \mathrm{sec}$. After comparing the first and the last (24th) result of each group, we did not observe an obvious change in the current, i.e., the results were repeating. After calculating the mean value with each gap distance, we found that unlike in the PBS trial results the current distinctively increased with the increase of voltage at the beginning (Fig. 1B), but the current intensities at $0.7 \mathrm{~V}$ of 7.5-28 m gap were 2.0, 1.84. 1.74, $1.68,1.62 \times 10^{-10} \mathrm{~A}$, respectively (standard deviations were approximately $10^{-12}$ ), almost
25-30 times lower than the results of the PBS trial. On the contrary, with a gap of $2.5 \mu \mathrm{m}$ (Fig. 1C), the current intensity $\left(1.2 \times 10^{-3} \mathrm{~A}\right.$ at $\left.0.7 \mathrm{~V}\right)$ was approximately 3.5 times higher than the PBS trial result $\left(3.46 \times 10^{-4} \mathrm{~A}\right.$ at $\left.0.7 \mathrm{~V}\right)$, and the current still showed a linear increase along with the increase of voltage. The nucleic acid surface carries negative charges, which might 'capture' positive ions that were moving to the cathode. As a result, with the larger gaps, the currents decreased. However, this did not happen with the $2.5-\mu \mathrm{m}$ gap. First, the two fused sheaths wield more influence on the current. Since the voltage in a unit of length was higher, the dismissing of double strands is relatively simple. It was considered that there may have been a few single-strand RNA molecules in the solution which caused the current to increase slightly.

Cell elution via controlled flow. Cheung et al (22) found that the detachment of antibody-captured cells depends on flow rate and flow acceleration, and the correlation between flow rate and detachment of attached cells is a log-normal distribution. In previous studies, it has been demonstrated that the aptamer biochip could efficiently isolate EGFRoverexpressing cancer cells $(21,22,30)$. Conversely, normal cells such as fibroblasts maintained their spherical shape in the suspension as the hydrophilic surface of the biochip prevents the physical attachment of the cells; or few of them attach to the surface due to their heavy weight and large size. In this experiment, fibroblasts were used as the control for nonspecific attached cancer cell elution. A low density of fibroblast suspension (approximately $3 \times 10^{4}$ cell $/ \mathrm{ml} ; 6 \mu \mathrm{l}$ ) was injected into the channel. Following incubation, the device was connected to a syringe pump via tubing filled with $1 \mathrm{x}$ PBS). A rate of $0.06 \mathrm{ml} / \mathrm{min}^{2}$ was selected for flow acceleration; $2 \mathrm{sec}$ later, when the average rate reached $0.12 \mathrm{ml} / \mathrm{min}$, almost all fibroblasts could be dislodged from the surface. After that, we used a constant flow rate of $0.12 \mathrm{ml} / \mathrm{min}$ to flush the unattached fibroblasts. A few of them, with an average diameter over $40 \mu \mathrm{m}$, were able to remain on the surface. We used the same process to remove the redundant mouse-derived tumor cells in the suspension and the nonspecifically attached ones on the surface to ensure the cells used for resistance detection were captured by the aptamer. Following resistance detection, if cells need to be eluted for further research, the parameters of flow rate and flow acceleration are not significant. In our practical experiment, a $0.3 \mathrm{ml} / \mathrm{min}^{2}$ flow acceleration and a $0.9 \mathrm{ml} / \mathrm{min}$ flow rate were used to flush the captured cancer cells.

Cell resistance detection. After washing with sterilized 1x PBS, we measured the cell resistance. All measurements were completed within $2 \mathrm{~h}$ to ensure that the cells were alive. Although the cell size was around $18-30 \mu \mathrm{m}$, we did not find any cell that could cover the 18,23 and $28-\mu$ m gaps between the two electrodes. In two biochips, we found 26 cells in the $2.5-\mu \mathrm{m}$ gap, 9 cells in the $7.5-\mu \mathrm{m}$ gap, and 1 cell in the $13-\mu \mathrm{m}$ gap. Although the cell resistance in the $13-\mu \mathrm{m}$ gap was close to that of the two previous groups, the result was not repeatable and therefore we did not adopt this datum for analysis. The mean value of the current was calculated respectively, and the relevant IV curves are shown in Fig. 1D. Firstly, it should be noted that the IV curve revealed the high resistance 
property of the cells. In particular, the current in $2.5-\mu \mathrm{m}$ gap decreased greatly. With a gap of $2.5 \mu \mathrm{m}$, the current increased from $3.10 \times 10^{-12} \mathrm{~A}(0 \mathrm{~V})$ to $1.38 \times 10^{-10} \mathrm{~A}(0.7 \mathrm{~V})$. With a gap of $7.5 \mu \mathrm{m}$, the current increased from $-6.61 \times 10^{-12} \mathrm{~A}(0 \mathrm{~V})$ to $1.26 \times 10^{-10} \mathrm{~A}(0.7 \mathrm{~V})$. Second, the current results between each single cell had a marked difference. The standard deviation also revealed this difference. With a $2.5-\mu \mathrm{m}$ gap, the standard deviation increased from $1.67 \times 10^{-13} \mathrm{~A}(0 \mathrm{~V})$ to $1.54 \times 10^{-11} \mathrm{~A}$ $(0.7 \mathrm{~V})$. In the $7.5-\mu \mathrm{m}$ gap, it increased from $5.29 \times 10^{-13} \mathrm{~A}$ $(0 \mathrm{~V})$ to $5.01 \times 10^{-11} \mathrm{~A}(0.7 \mathrm{~V})$. Since we only obtained 9 cells with the $7.5 \mu \mathrm{m}$ gap, and there was no distinguishable difference in the average current between the two gaps, we did not consider the gap distance to have a prominent effect on the current, unlike in the previous results. The variation may be caused by the cell itself (its size, maturity, etc.). Third, the current values from the two gap distances were very close compared with the huge difference between them in the PBS and DNA-RNA background experiment. This indicates that the cell is the conductor between the two electrodes, and that most of the current flowed through the cell but not the PBS and DNA-RNA complex. Fourth, the IV curves were no longer smooth, but rough. In our experiment, we kept the voltage constantly increasing in one electrode, and kept the other one constant. At resting state, the inner and outer cell membranes carry a negative and positive charge respectively, and cells stay at resting potential. The increasing voltage gave stimulation to the cells, and in response cells form a swift and short potential fluctuation. This fluctuation can spread to surrounding cells, and creates action potential. Locally, current can form in this way. After action potential, the cell will drop back into resting potential again for the next stimulation. This phenomenon is particularly prominent in neural and muscle cells. In tumor cells, the situation becomes more complex, since the density and amount of sialylation on the cancer cell surface is higher than in normal cells (31). Carboxyl group from the sialic acid causes negative surface charge of tumor cells. The cells with negative surface charge and potential under the increasing voltage stimulation finally formed the curve shown in Fig. 1D. We also noted that the curves are not always rough. Some parts of the curves are relatively smooth. This may be caused by the uneven voltage increasing speed, and the cell membrane 'fatigue'. As the data showed here, the current did not change much with a gap of $7.5 \mu \mathrm{m}$, but demonstrated a great decrease with the $2.5-\mu \mathrm{m}$ gap; therefore, we chose to adopt this size for further experiments. After finishing the first time measurement, we attempted to seed the tumor cells on the surface again and investigated whether the biochip could capture the tumor cells again. After $30 \mathrm{~min}$ incubation, many cells were still suspended. Although we still observed a few cells on the surface after washing, the cell density was much lower. We surmised that DNA or RNA may be degraded by enzymes which may be exogenetic or from the cell itself during the incubation and eluting process; and/or the DNA-RNA complex denatured by electric field force during the resistance detection. The problem we encountered in this experiment was the location of captured cells. When we seeded cells on the surface, we had no method of controlling their attachment location; this was why we only measured the resistance in 37 cells. However, the results were easily repeatable and reliable. In the next step, we need to consider how to effectively isolate the cell at an appointed location for further resistance detection.

\section{Discussion}

In this study, we utilized the property of anti-EGFR aptamer to specifically recognize and capture cancer cells overexpressing EGFR to detect single cell resistance. Once the cell was captured and lodged between the gaps of two electrodes, its resistance could be detected. After studying the gap size and PBS and DNA-RNA conductibility, the results show that the current dramatically changed before and after the cell was captured in the $2.5-\mu \mathrm{m}$ gap. This change can be used in cell counting in other experiments. Controlled flow acceleration and flow rate can be used for flushing specific/nonspecific attached cancer and normal cells. This novel aptamer biochip could be used for isolation of circulating tumor cells from peripheral blood and cell counting, or be assembled with other lab-on-chip components for follow-up gene and protein analysis.

\section{References}

1. Horan PK and Wheeless LL: Quantitative single cell analysis and sorting. Science 198: 149-157, 1977.

2. Wheeler AR, Throndset WR, Whelan RJ, Leach AM, Zare RN, Liao YH, Farrell K, Manger ID and Daridon A: Microfluidic device for single-cell analysis. Electrophoresis 22: 283-288, 2001.

3. Bucy RP, Karr L, Huang G, Li J, Carter D, Honjo K, Lemons JA, Murphy KM and Weaver CT: Single cell analysis of cytokine gene coexpression during CD4+ T-cell phenotype development. Proc Natl Acad Sci 92: 7565-7569, 1995.

4. Shapiro HM: Practical Flow Cytometry. John Wiley \& Sons, New York, NY, 1988.

5. Ozkan M, Wang M, Ozkan C, Flynn R and Esener S: Optical manipulation of objects and biological cells in microfluidic devices. Biomedical Microdevices 5: 61-67, 2003.

6. Harrison DJ, Fluri K, Seiler K, Fan Z, Effenhauser CS and Manz A: Micromachining a miniaturized capillary electrophoresis-based chemical analysis system on a chip. Science 261: 895-897, 1993.

7. Fiedler S, Shirley SG, Schnelle T and Fuhr G: Dielectrophoretic sorting of particles and cells in a microsystem. Anal Chem 70: 1909-1915, 1998.

8. Cai X, Klauke N, Glidle A, Cobbold P, Smith GL and Cooper JM: Ultra-low-volume, real-time measurements of lactate from the single heart cell using microsystems technology. Anal Chem 74: 908-914, 2002.

9. Gomez R, Bashir R and Bhunia AK: Microscale electronic detection of bacterial metabolism. Sensors \& Actuators: B Chemical 86: 198-208, 2002.

10. Huang WH, Cheng W, Zhang Z, Pang DW, Wang ZL, Cheng JK and Cui DF: Transport, location, and quantal release monitoring of single cells on a microfluidic device. Anal Chem 76: 483-488, 2004.

11. Prabhulkar S, Alwarappan S, Liu G and Li CZ: Amperometric micro-immunosensor for the detection of tumor biomarker. Biosens Bioelectron 24: 3524-3530, 2009.

12. Zhang L, Qv S, Wang Z and Cheng J: Determination of dopamine in single rat pheochromocytoma cell by capillary electrophoresis with amperometric detection. J Chromatogr B Technol Biomed Life Sci 792: 381-385, 2003.

13. Zou Z, Ka J, Rust MJ, Han J and Ahn CH: Functionalized nano interdigitated electrodes arrays on polymer with integrated microfluidics for direct bio-affinity sensing using impedimetric measurement. Sensors \& Actuators: A Physical 136: 518-526, 2007.

14. Olsen EV, Pathirana ST, Samoylov AM, Barbaree JM, Chin BA, Neely WC and Vodyanoy V: Specific and selective biosensor for Salmonella and its detection in the environment. J Microbiol Methods 53: 273-285, 2003. 
15. Radke SM and Alocilja EC: A high density microelectrode array biosensor for detection of $E$. coli O157: H7. Biosens Bioelectron 20: 1662-1667, 2005.

16. Suehiro J, Noutomi D, Shutou M and Hara M: Selective detection of specific bacteria using dielectrophoretic impedance measurement method combined with an antigen-antibody reaction. J Electrostatics 58: 229-246, 2003.

17. Yang L, Li Y and Erf GF: Interdigitated array microelectrode-based electrochemical impedance immunosensor for detection of Escherichia coli O157: H7. Anal Chem 76: 1107-1113, 2004

18. Dalle F, Lopez J, Caillot D, Cuisenier B, Ecarnot Laubriet A, Dumont L and Bonnin A: False-positive results caused by cotton swabs in commercial aspergillus antigen latex agglutination test. Eur J Clin Microbiol Infect Dis 21: 130-132, 2002.

19. Cho EJ, Lee JW and Ellington AD: Applications of aptamers as sensors. Annu Rev Anal Chem 2: 241-264, 2009.

20. Bunka DHJ and Stockley PG: Aptamers come of age - at last. Nat Rev Microbiol 4: 588-596, 2006.

21. Wan Y, Kim YT, Li N, et al: Surface-immobilized aptamers for cancer cell isolation and microscopic cytology. Cancer Res 70: 9371-9380, 2010.

22. Wan Y, Mahmood MA, Li N, et al: Nanotextured substrates with immobilized aptamers for cancer cell isolation and cytology Cancer 118: 1145-1154, 2012.

23. Cheung LSL, Zheng X, Stopa A, Baygents JC, Guzman R, Schroeder JA, Heimark RL and Zohar Y: Detachment of captured cancer cells under flow acceleration in a bio-functionalized microchannel. Lab Chip 9: 1721-1731, 2009.

24. Martin RS, Gawron AJ, Lunte SM and Henry CS: Dual-electrode electrochemical detection for poly (dimethylsiloxane)-fabricated capillary electrophoresis microchips. Anal Chem 72: 3196-3202, 2000
25. Iqbal SM, Akin D and Bashi R: Solid-state nanopore channels with DNA selectivity. Nat Nanotechnol 2: 243-248, 2007.

26. Moller R, Csaki A, Kohler JM and Fritzsche W: DNA probes on chip surfaces studied by scanning force microscopy using specific binding of colloidal gold. Nucleic Acids Res 28: e91, 2000.

27. Farokhzad OC, Jon S, Khademhosseini A, Tran TNT, LaVan DA and Langer R: Nanoparticle-aptamer bioconjugates: a new approach for targeting prostate cancer cells. Cancer Res 64: 7668-7672, 2004.

28. Wan Y, Wang Y, Luo JF and Lu ZH: Bisulfite modification of immobilized DNAs for methylation detection. Biosens Bioelectron 22: 2415-2421, 2007.

29. Xiao PF, Cheng L, Wan Y, Sun BL, Chen ZZ, Zhang SY, Zhang CZ, Zhou GH and Lu ZH: An improved gel-based DNA microarray method for detecting single nucleotide mismatch. Electrophoresis 27: 3904-3915, 2006.

30. Wan Y, Tan J, Asghar W, Kim YT, Liu Y and Iqbal SM: Velocity effect on aptamer-based circulating tumor cell isolation in microfluidic devices. J Phys Chem B 115: 13891-13896, 2011.

31. Khadapkar SV, Sheth NA and Bhide SV: Independence of sialic acid levels in normal and malignant growth. Cancer Res 35: $1520-1523,1975$ 